\title{
Physiological Actions of Fibroblast Growth Factor-23
}

\author{
Reinhold G. Erben* \\ Department of Biomedical Sciences, University of Veterinary Medicine Vienna, Vienna, Austria
}

\section{OPEN ACCESS}

Edited by:

Andreas Hoeflich, Leibniz-Institut für Nutztierbiologie (FBN), Germany

Reviewed by:

Nan E. Hatch, University of Michigan, United States

Andrew C. B. Cato, Karlsruher Institut für Technologie, Germany

${ }^{*}$ Correspondence:

Reinhold G. Erben reinhold.erben@vetmeduni.ac.at

Specialty section: This article was submitted to Molecular and Structural Endocrinology, a section of the journal Frontiers in Endocrinology

Received: 08 March 2018 Accepted: 08 May 2018 Published: 28 May 2018

Citation:

Erben RG (2018) Physiological Actions of Fibroblast Growth

Factor-23.

Front. Endocrinol. 9:267. doi: 10.3389/fendo.2018.00267
Fibroblast growth factor-23 (FGF23) is a bone-derived hormone suppressing phosphate reabsorption and vitamin $\mathrm{D}$ hormone synthesis in the kidney. At physiological concentrations of the hormone, the endocrine actions of FGF23 in the kidney are aKlothodependent, because high-affinity binding of FGF23 to FGF receptors requires the presence of the co-receptor $\alpha$ Klotho on target cells. It is well established that excessive concentrations of intact FGF23 in the blood lead to phosphate wasting in patients with normal kidney function. Based on the importance of diseases associated with gain of FGF23 function such as phosphate-wasting diseases and chronic kidney disease, a large body of literature has focused on the pathophysiological consequences of FGF23 excess. Less emphasis has been put on the role of FGF23 in normal physiology. Nevertheless, during recent years, lessons we have learned from loss-of-function models have shown that besides the paramount physiological roles of FGF23 in the control of $1 \alpha$-hydroxylase expression and of apical membrane expression of sodium-phosphate co-transporters in proximal renal tubules, FGF23 also is an important stimulator of calcium and sodium reabsorption in distal renal tubules. In addition, there is an emerging role of FGF23 as an auto-/paracrine regulator of alkaline phosphatase expression and mineralization in bone. In contrast to the renal actions of FGF23, the FGF23-mediated suppression of alkaline phosphatase in bone is $\alpha$ Klotho-independent. Moreover, FGF23 may be a physiological suppressor of differentiation of hematopoietic stem cells into the erythroid lineage in the bone microenvironment. At present, there is little evidence for a physiological role of FGF23 in organs other than kidney and bone. The purpose of this mini-review is to highlight the current knowledge about the complex physiological functions of FGF23.

Keywords: fibroblast growth factor-23, Klotho, vitamin D, 1 $\alpha$-hydroxylase, bone mineralization, phosphate metabolism, alkaline phosphatase

\section{INTRODUCTION}

In the year 2000, gain-of-function mutations in fibroblast growth factor-23 (FGF23) were identified as the genetic cause of autosomal dominant hypophosphatemic rickets (ADHR), an inherited renal phosphate-wasting disease (1). In the following years, FGF23 turned out to be the long-sought "phosphatonin" that had already been postulated in the 1980s, when parabiosis experiments in hypophosphatemic Hyp mice had shown that the renal phosphate wasting and the hypophosphatemia in these mice were caused by a factor circulating in the blood (2).

Fibroblast growth factor- 23 is a $32 \mathrm{kDa}$ glycoprotein mainly produced in bone by osteoblasts and osteocytes under physiological circumstances. FGF23 is inactivated by cleavage at the ${ }^{176} \mathrm{RXXR}^{179}$ site, a site that is mutated in ADHR patients. Together with FGF19 and FGF21, FGF23 belongs to 
the group of endocrine FGFs (3). All endocrine FGFs require the co-receptors $\alpha$ - and $\beta$-Klotho for high-affinity binding to the ubiquitously expressed FGF receptors (FGFR1-4) in target cells (4-7). The co-receptor needed for binding of FGF23 to FGF receptors is transmembrane or soluble $\alpha$ Klotho $(4,8)$. Among the four different FGFRs, FGF receptor-1c (FGFR1c) is probably the most important FGFR for FGF23 signaling, at least under physiological conditions $(4,9)$. $\alpha$ Klotho enhances the binding affinity of FGFR1c to FGF23 by a factor of approximately 20 (6). The " $\mathrm{c}$ " in FGFR1 stands for a splice variant which occurs in FGFR1, 2, and 3 .

The principal action of FGF23 on mineral metabolism that led to its discovery as a hormone is the suppressive effect on phosphate reabsorption from the urine $(10,11)$. In addition, FGF23 suppresses the synthesis of the vitamin D hormone, $1 \alpha$, 25 -dihydroxyvitamin $\mathrm{D}_{3}\left[1,25(\mathrm{OH})_{2} \mathrm{D}_{3}\right]$, in the kidney $(10,11)$. It is now well known that diseases characterized by excessive blood concentrations of intact FGF23 lead to renal phosphate wasting and inappropriately low-circulating $1,25(\mathrm{OH})_{2} \mathrm{D}_{3}$ levels in patients with a normal kidney function (12). Examples of human disorders associated with elevated intact FGF23 are ADHR with a defective cleavage site of FGF23, X-linked hypophosphatemic rickets (XLH), and autosomal recessive hypophosphatemic rickets 1 (ARHR1) caused by overproduction of FGF23 in bone, and tumor-induced osteomalacia caused by FGF23-producing tumors (12). The molecular mechanism underlying the increased bony FGF23 secretion in XLH and ARHR1 patients is still unclear. In terms of factors that may drive FGF23 secretion, the common denominator in both diseases is impaired bone mineralization. $\mathrm{XLH}$ is caused by loss-of-function mutations in PHEX (13). It has been shown in Hyp mice, the murine model of XLH, that lack of the endopeptidase PHEX leads to accumulation of osteopontin and ASARM (acidic serine- and aspartate-rich MEPE-associated motif) peptides in the matrix, which both inhibit mineralization (14-17). ARHR1 is caused by loss-of-function mutations in dentin matrix protein-1, which is required for normal mineralization of bone (18). It is currently believed that the excessive osteocytic and osteoblastic FGF23 secretion in both diseases is either driven by the impaired mineralization of the extracellular matrix, which may be detected by matrix-embedded bone cells through a putative sensing mechanism that may involve FGF receptors $(19,20)$, or by an altered set point for phosphate sensing in bone cells $(21,22)$. Circulating intact FGF23 is also elevated in patients with chronic kidney disease (CKD), and can reach blood levels as high as 1,000-fold above the normal range $(23,24)$. Although elevated intact FGF23 may help to maintain normophosphatemia in early stages of CKD, serum phosphate levels typically increase at later stages of the disease despite very high-serum intact FGF23. Therefore, in the setting of impaired kidney function, the phosphaturic action of FGF23 is not able to correct the hyperphosphatemia in more advanced CKD.

Collectively, there is very good evidence that gain of FGF23 function results in renal phosphate wasting in patients with normal kidney function. However, what is the role of FGF23 in normal physiology? The purpose of this mini-review is to answer this question, and to highlight the current knowledge about the complex physiological functions of FGF23 in mice and men.

\section{PHYSIOLOGICAL FUNCTIONS OF FGF23 IN THE KIDNEY}

Knockout experiments in mice have revealed that the paramount physiological function of FGF23 is not its phosphaturic function, but its suppressive role in the control of renal $1 \alpha$-hydroxylase (CYP27B1) transcription, the key enzyme for $1,25(\mathrm{OH})_{2} \mathrm{D}_{3}$ synthesis. Notably, in the absence of the ligand FGF23 or of its co-receptor $\alpha$ Klotho, the stringent endocrine control of $1 \alpha$-hydroxylase transcription fails, leading to inappropriately high expression and activity of this enzyme. The sequel of $1 \alpha$-hydroxylase overexpression are elevated $1,25(\mathrm{OH})_{2} \mathrm{D}_{3}$ levels, causing hypercalcemia, hyperphosphatemia, ectopic calcifications, impaired bone mineralization, and early lethality in $\alpha$ Klotho and Fgf23 deficient mice (25-27). The major function of $1,25(\mathrm{OH})_{2} \mathrm{D}_{3}$ in mineral metabolism is the stimulation of intestinal calcium and phosphorus absorption. The crucial role of $1,25(\mathrm{OH})_{2} \mathrm{D}_{3}$ overproduction in mediating the phenotype of $\alpha \mathrm{Klotho}^{-/-}$and $\mathrm{Fgf23^{-/- }}$ mice is underscored by the well documented finding that ablation of vitamin $\mathrm{D}$ signaling almost completely rescues the phenotype of $\mathrm{Fg} f 23^{-/-}$and $\alpha \mathrm{Klotho}^{-/-}$mice (28-30). In analogy to the phenotype of $\alpha$ Klotho and Fgf23 deficient mice, humans with loss-of-function mutations in FGF23 or $\alpha$ Klotho are characterized by elevated circulating vitamin $\mathrm{D}$ hormone levels and soft tissue calcifications (31-34), corroborating the mouse data.

Despite the pivotal physiological importance of the FGF23mediated suppression of $1 \alpha$-hydroxylase transcription, the knowledge of the intracellular signaling pathway involved in this regulation is still fragmentary. Expression of $1 \alpha$-hydroxylase is mainly localized in proximal renal tubules. Proximal and distal renal tubules express the co-receptor $\alpha$ Klotho as well as FGFR1, 3 , and 4, but only little FGFR2 $(35,36)$. All FGFRs are receptor tyrosine kinases, initiating intracellular phosphorylation cascades after ligand-induced dimerization (37). Mice with a specific deletion of $\mathrm{Fgfr} 1$ in proximal renal tubules are resistant to the FGF23-induced suppression of $1,25(\mathrm{OH})_{2} \mathrm{D}_{3}$ production (9). Therefore, FGFR1c is probably the predominant FGFR mediating the suppressive effects of FGF23 on renal tubular $1,25(\mathrm{OH})_{2} \mathrm{D}_{3}$ synthesis (Figure 1). However, to a lesser extent, FGFR3 and 4 may also be involved, because genetic ablation of $\mathrm{Fg} f \mathrm{r} 3$ and $\mathrm{Fg} f \mathrm{r} 4$ increases renal $1 \alpha$-hydroxylase expression in Hyp mice, which are characterized by increased endogenous FGF23 production (38). There is good evidence that the FGF23-mediated suppression of $1 \alpha$-hydroxylase transcription involves extracellular signal-regulated kinase-1 and -2 (ERK1/2) activation $(39,40)$, but the exact signaling pathway downstream of ERK1/2 is unknown (Figure 1). Interestingly, the FGF23-mediated control of the transcriptional activity of the $1 \alpha$-hydroxylase gene occurs through regulatory elements located in introns of the neighboring Mettl21b gene (41). However, the transcription factor(s) involved in this regulation are currently unknown. It is only clear in this context that FGF23 regulates $1 \alpha$-hydroxylase in a $1,25(\mathrm{OH})_{2} \mathrm{D}_{3}$ and vitamin D receptor (VDR) independent manner (42).

It is well established that parathyroid hormone (PTH) and FGF23 regulate $1 \alpha$ - and 24 -hydroxylase (CYP24A1) expression reciprocally. FGF23 suppresses $1 \alpha$-hydroxylase, but induces 24-hydroxylase expression. PTH has the opposite effects. 


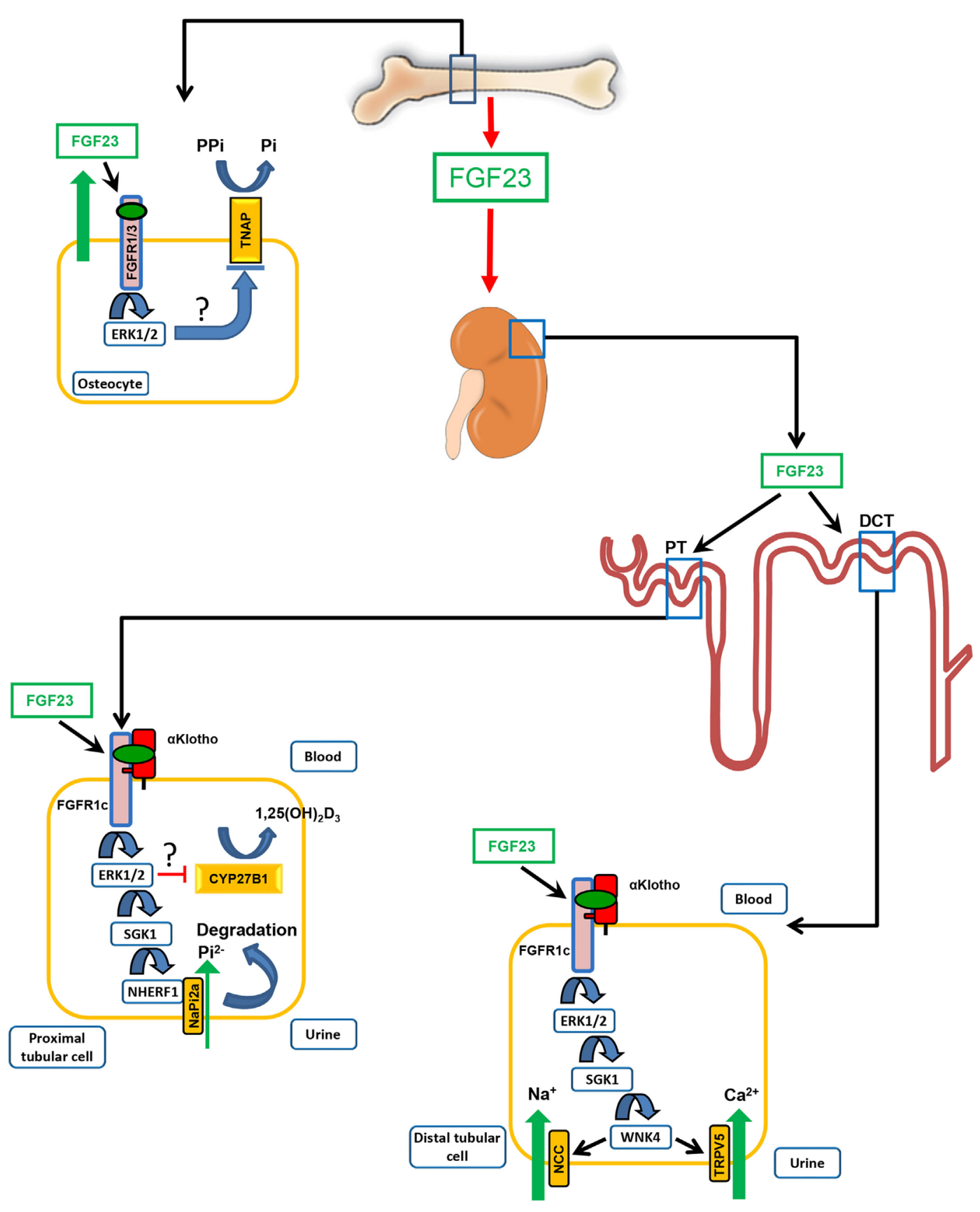

FIGURE 1 | Physiological functions of fibroblast growth factor-23 (FGF23). FGF23 is mainly produced in bone cells, osteoblasts, and osteocytes. One of the main target organs of the hormone FGF23 is the kidney. In the kidney, FGF23 acts on proximal and distal convoluted renal tubules. Binding of blood-borne FGF23 to FGF receptor-1c (FGFR1c) requires the presence of the co-receptor $\alpha$ Klotho. In renal proximal tubules (PT), FGF23 inhibits phosphate (Pi) re-uptake and expression of $1 \alpha$-hydroxylase (CYP27B1), the rate-limiting enzyme for vitamin D hormone $\left(1 \alpha, 25(\mathrm{OH})_{2} \mathrm{D}_{3}\right)$ production. The FGF23-mediated suppression of $1 \alpha$-hydroxylase transcription involves extracellular signal-regulated kinase-1 and 2 (ERK1/2) activation. However, the exact signaling pathway downstream of ERK1/2 is unknown. The inhibition of phosphate reabsorption in proximal renal tubules by FGF23 is mediated through activation of ERK1/2 and serum/glucocorticoid-regulated kinase-1 (SGK1), leading to phosphorylation of the scaffolding protein $\mathrm{Na}^{+} / \mathrm{H}^{+}$exchange regulatory cofactor (NHERF)-1. NHERF-1 phosphorylation triggers internalization and degradation of the sodium-phosphate cotransporter NaPi-2a, so that less NaPi-2a is available in the apical membrane for phosphate uptake from urine. In distal convoluted tubules (DCT), FGF23 increases reabsorption of calcium and sodium by increasing the apical membrane abundance of the epithelial calcium channel transient receptor potential vanilloid-5 and of the sodium-chloride cotransporter NCC through a signaling cascade involving ERK1/2, SGK1, and with-no-lysine kinase-4 (WNK4). FGF23 locally produced by osteocytes is an auto-/paracrine inhibitor of bone mineralization by down-regulating tissue non-specific alkaline phosphatase (TNAP) transcription in a $\alpha$ Klotho-independent fashion via FGFR1- or FGFR3-mediated activation of ERK1/2. The signaling pathway downstream of ERK1/2, leading to suppression of TNAP transcription, is not known. TNAP is essential for normal mineralization of bone by cleaving the mineralization inhibitor pyrophosphate (PPi). 
$1 \alpha$-hydroxylation represents metabolic conversion of the precursor 25-hydroxyvitamin $\mathrm{D}$ into the biologically active hormone, whereas 24-hydroxylation is an inactivation pathway (43). $1,25(\mathrm{OH})_{2} \mathrm{D}$ is known to be a strong inducer of 24 -hydroxylase (43), stimulating its own degradation. Whether FGF23 is a direct regulator of 24-hydroxylase transcription has been a controversial issue for many years. Some reports in $\mathrm{Fgf23} \mathrm{3}^{-/-}$ mice (26) as well as in wild-type mice treated with recombinant FGF23 (11) suggested that FGF23 signaling may directly induce 24-hydroxylase, whereas experiments in VDR knockout mice suggested that the FGF23-mediated regulation of 24-hydroxylase is not direct, but depends on the $\operatorname{VDR}(42,44)$. The latter notion has been confirmed by recent evidence showing that, in contrast to the $1,25(\mathrm{OH})_{2} \mathrm{D}_{3}$-mediated induction, both the FGF23-mediated induction and the PTH-mediated suppression of 24-hydroxylase are completely lost in $1 \alpha$-hydroxylase knockout mice (41). This finding strongly suggests that the FGF23 and PTH-mediated regulation of 24-hydroxylase expression are entirely indirect through altered $1,25(\mathrm{OH})_{2} \mathrm{D}_{3}$ synthesis and subsequent changes in VDR-regulated promoter activity of 24-hydroxylase.

As mentioned above, FGF23 promotes renal phosphate excretion by inhibiting cellular phosphate re-uptake from the urine in proximal renal tubules (Figure 1). Through a signaling cascade involving the $\alpha$ Klotho/FGFR1c receptor complex, ERK1/2, and serum/glucocorticoid-regulated kinase-1 (SGK1), FGF23 signaling induces the phosphorylation of the scaffolding protein $\mathrm{Na}^{+}$/ $\mathrm{H}^{+}$exchange regulatory cofactor (NHERF)-1 which in turn leads to internalization and degradation of the sodium-phosphate cotransporters NaPi-2a and NaPi-2c $(36,45,46)$. Notably, 4-weekold Fgf23 ${ }^{-/-} / \mathrm{VDR}^{\Delta / \Delta}$ (Fgf23/VDR) and $\alpha$ Klotho $^{-/-} / \mathrm{VDR}^{\Delta / \Delta}$ (Klotho/VDR) compound mutant mice lacking Fgf23 or Klotho and a functioning VDR are not hyperphosphatemic $(28,29,47)$. Hyperphosphatemia is only seen in older, more slowly or nongrowing Fgf23/VDR compound mutant mice beyond 3 months of age $(30,47)$, suggesting that the phosphaturic effect of FGF23 is physiologically less essential compared with the $1 \alpha$-hydroxylasesuppressing effect, at least in mice. Both the phosphaturic and the $1,25(\mathrm{OH})_{2} \mathrm{D}_{3}$-lowering effect of FGF23 protect against hyperphosphatemia: the first effect directly through increased elimination of phosphate, and the second effect indirectly through reduced intestinal phosphate absorption. In addition, because $1,25(\mathrm{OH})_{2} \mathrm{D}_{3}$ and phosphate stimulate FGF23 secretion in bone (12), the phosphaturic and $1,25(\mathrm{OH})_{2} \mathrm{D}_{3}$-lowering effects of FGF23 form a negative feedback loop between bone and kidney.

In recent years, it has become clear that FGF23 is not only a regulator of vitamin $\mathrm{D}$ and phosphate metabolism, but also directly influences calcium and sodium handling in the distal nephron in the kidney (Figure 1). Skeletally mature Fgf23/VDR and Klotho/VDR compound mutant mice are characterized by renal calcium wasting (48), as well as by renal sodium wasting and subsequent hyponatremia, hypovolemia, and hypotension (49). Similar to proximal renal tubules, the FGFR1c/Klotho complex appears to be the most important receptor complex in the distal nephron, because distal tubular-specific deletion of Fgfr1 recapitulates the renal calcium wasting seen in Fgf23/VDR compound mutant mice (9). In distal tubular epithelium, FGF23 regulates the apical membrane abundance of the epithelial calcium channel transient receptor potential vanilloid-5 (TRPV5) and of the sodium-chloride cotransporter NCC through a signaling cascade involving ERK1/2, SGK1, and with-no-lysine kinase-4 $(48,49)$. Fgf23 and Klotho deficient mice are characterized by a downregulation of distal tubular TRPV5 and NCC membrane expression, leading to renal calcium and sodium wasting, despite counter-regulatory increases in circulating PTH and aldosterone (48-50). These findings indicate that the calcium- and sodiumconserving functions of FGF23 in distal renal tubules are of physiological relevance. Indeed, the increased renal conservation of calcium may help to maintain blood calcium levels despite the suppression of $1,25(\mathrm{OH})_{2} \mathrm{D}_{3}$ synthesis induced by upregulated FGF23 secretion. In single Fgf23 and Klotho knockout mice, the calcium-conserving function of FGF23 is masked by the profound upregulation of $1,25(\mathrm{OH})_{2} \mathrm{D}_{3}$ production and subsequent hypercalcemia.

Parathyroid hormone and FGF23 have partially overlapping functions in proximal and distal renal tubules. Both hormones inhibit phosphate reabsorption in proximal renal tubules by targeting NHERF-1 phosphorylation $(36,45,46)$, and increase calcium reabsorption in distal renal tubules by targeting expression and/or open probability of TRPV5 $(48,51)$. Albeit the signaling mechanisms are different, the proximal and distal renal target molecules of PTH and FGF23 are the same. An interesting finding in this context is that absence of FGF23 signaling in Fgf23 deficient mice causes partial renal resistance to the phosphaturic and calcium-conserving actions of PTH (50). Vice versa, a reduction in PTH signaling in human patients with hypoparathyroidism has been shown to induce partial resistance to the phosphaturic actions of FGF23 $(52,53)$. Therefore, both hormones interact, and an important physiological function of FGF23 may be to enable normal responsiveness to PTH signaling in the kidney and also in bone (50).

Taken together, lessons learned from knockout mouse models have revealed that the most important physiological function of FGF23 is not its phosphaturic effect but the downregulation of vitamin D hormone production. It is likely that the exquisite sensitivity of the homeostatic system regulating $1 \alpha$-hydroxylase transcription to lack of FGF23 signaling is caused by the absence of other suppressive hormones which might be able to effectively counter-balance FGF23 deficiency. In Fgf23 and Klotho deficient mice, the suppression of PTH secretion observed in these mice is insufficient to control transcription of renal $1 \alpha$-hydroxylase. In contrast, lack of the phosphaturic, as well as of the calcium- and sodium-conserving functions of FGF23 can at least partially be compensated by the phosphaturic and calcium-conserving hormone PTH, and by the sodium-conserving hormone aldosterone. Therefore, the pivotal importance of FGF23 signaling for the control of $1 \alpha$-hydroxylase transcription might be considered as a systems biology problem. This problem may also have implications for the treatment of patients with antibodies against FGF23 or with small molecules blocking the FGF23 signaling pathway. The therapeutic window for these treatments is relatively narrow, and requires close monitoring of calcium and phosphorus metabolism to avoid toxic side effects $(54,55)$. 


\section{PHYSIOLOGICAL FUNCTIONS OF FGF23 IN BONE}

Fibroblast growth factor-23 may also have physiologically relevant functions in bone on bone mineralization and on hematopoiesis. We recently reported that FGF23 is a powerful suppressor of transcription of tissue non-specific alkaline phosphatase (TNAP) mRNA in bone cells in a Klotho-independent manner (56) (Figure 1). TNAP is essential for the regulation of bone mineralization by cleaving the mineralization inhibitor pyrophosphate which is secreted by osteoblasts to prevent premature mineralization of osteoid (57). Based on experiments with pharmacological FGFR inhibitors, we concluded that the FGF23-induced, Klothoindependent suppression of TNAP mRNA abundance in primary murine osteoblasts is mainly mediated through FGFR3 (56). In contrast, Shalhoub et al. (58) reported that FGF23 suppresses TNAP expression in mouse osteoblast-like cells in an FGFR1-dependent manner, and that this effect could be enhanced by soluble Klotho. Thus, it awaits further clarification whether the FGF23-mediated suppression of TNAP in bone cells is mainly mediated through FGFR1, FGFR3, or both. Klotho expression in bone is very low $(33,59)$. Therefore, it is unlikely that Klotho expression in bone cells is sufficient to enhance FGF23 binding to FGFRs in osteoblasts and osteocytes. However, it can be assumed that due to the local production of FGF23 in osteocytes, the concentration of FGF23 within the canalicular system is high enough for auto-/paracrine, Klotho-independent signaling through FGFRs in bone. Hence, locally produced FGF23 may not only contribute to impaired mineralization under the conditions of excessive bony FGF23 secretion such as in Hyp mice (60), but may also serve as a physiological inhibitor of bone mineralization by downregulating TNAP expression. In line with this notion, we found an upregulation of Tnap mRNA abundance in Fgf23 deficient Fgf23/VDR compound mutant mice compared with wild-type and VDR control mice (56). However, the relevance of this mechanism in the context of physiological ranges of FGF23 secretion remains to be shown.

Fgf23 deficient mice are characterized by increased erythropoiesis (61). Conversely, injection of recombinant FGF23 into normal mice suppresses erythropoiesis (61), and inhibition of FGF23 signaling alleviates the suppression of erythropoiesis in mice with excessive FGF23 blood levels due to renal failure (62). Therefore, FGF23 may be a physiological regulator of erythroid lineage commitment in the bone microenvironment. However, the signaling mechanisms underlying this effect are currently not known, and further studies are needed to demonstrate the relevance of this effect in relation to the physiological regulation of erythropoiesis by the renal hormone erythropoietin.

\section{PHYSIOLOGICAL FUNCTIONS OF FGF23 IN OTHER ORGANS?}

It is interesting to note that the first description of FGF23 was actually in thalamic nuclei in the murine brain (63). However, data about possible functions of FGF23 in the brain are still scarce. It was reported that high concentrations of FGF23 may interfere with neuronal ramification and may increase synaptic density in cultures of hippocampal neurons (64), but very little is known about potential physiological functions. Fgf23/VDR compound mutant mice do not have an overt CNS phenotype until older ages (30), but more elaborate behavioral or cognitive tests have never been done.

The parathyroid gland is one of the organs abundantly expressing $\alpha$ Klotho $(33,65)$, making it a potential target tissue for FGF23. However, conditional knockout mice with a parathyroid-specific deletion of $\alpha$ Klotho show normal circulating intact PTH levels (65). In addition, global Fgf23/VDR and $\alpha$ Klotho/VDR mutant mice at young ages do not show differences in PTH blood concentrations compared with VDR mutant mice $(28,29)$. Only at older ages, PTH secretion is upregulated in Fgf23/VDR and $\alpha$ Klotho/VDR mutant mice, relative to VDR controls, in response to chronic renal calcium wasting and partial PTH resistance (50). Hence, although high-FGF23 blood concentrations may suppress PTH secretion in a Klotho-independent fashion in rodents $(65,66)$, it is unlikely that FGF23 signaling has an important role in the physiological regulation of $\mathrm{PTH}$ secretion.

Although the heart may be an important target tissue at supraphysiological FGF23 concentrations, promoting cardiomyocyte hypertrophy in CKD patients by a Klotho-independent signaling pathway $(67,68)$, FGF23 is not expressed in the normal heart, and heart function is normal in Fgf23/VDR mutant mice (69). These findings suggest that FGF23 does not have a functional role in the heart under physiological circumstances.

Taken together, there is only little evidence that FGF23 has a role in normal physiology in organs other than kidney and bone.

\section{CONCLUSION}

The purpose of this mini-review is to highlight the current knowledge about the physiological functions of the bone-derived hormone FGF23. Excessive circulating intact FGF23 levels result in renal phosphate wasting under the conditions of a normal kidney function. However, knockout mouse models have shown that the most important physiological function of FGF23 is not the phosphaturic effect, but the suppressive effect on renal $1 \alpha$-hydroxylase expression. The absence of FGF23 or of its co-receptor $\alpha$ Klotho results in deregulated renal $1 \alpha$-hydroxylase expression and vitamin $\mathrm{D}$ hormone production, which cannot be compensated by other endocrine systems. Moreover, FGF23 has several additional physiological functions, which include inhibition of renal phosphate reabsorption, increased conservation of calcium and sodium in the kidney, support of a normal responsiveness of the kidney to PTH, and regulation of bone mineralization. Although excessive FGF23 may target many non-canonical tissues, there is currently little evidence for a role of FGF23 in the normal physiology of organs other than kidney and bone.

\section{AUTHOR CONTRIBUTIONS}

The author confirms being the sole contributor of this work and approved it for publication.

\section{FUNDING}

This work was supported by a grant from the Austrian Science Fund (FWF P24186-B21) to RE. 


\section{REFERENCES}

1. ADHR Consortium. Autosomal dominant hypophosphataemic rickets is associated with mutations in FGF23. Nat Genet (2000) 26:345-8. doi:10.1038/81664

2. Meyer RA Jr, Meyer MH, Gray RW. Parabiosis suggests a humoral factor is involved in X-linked hypophosphatemia in mice. J Bone Miner Res (1989) 4:493-500. doi:10.1002/jbmr.5650040407

3. Itoh $\mathrm{N}$, Ohta $\mathrm{H}$, Konishi M. Endocrine FGFs: evolution, physiology, pathophysiology, and pharmacotherapy. Front Endocrinol (2015) 6:154. doi:10.3389/fendo.2015.00154

4. Urakawa I, Yamazaki Y, Shimada T, Ijima K, Hasegawa H, Okawa K, et al. Klotho converts canonical FGF receptor into a specific receptor for FGF23. Nature (2006) 444:770-4. doi:10.1038/nature05315

5. Goetz R, Beenken A, Ibrahimi OA, Kalinina J, Olsen SK, Eliseenkova AV, et al. Molecular insights into the Klotho-dependent, endocrine mode of action of fibroblast growth factor 19 subfamily members. Mol Cell Biol (2007) 27:3417-28. doi:10.1128/MCB.02249-06

6. Goetz R, Ohnishi M, Kir S, Kurosu H, Wang L, Pastor J, et al. Conversion of a paracrine fibroblast growth factor into an endocrine fibroblast growth factor. J Biol Chem (2012) 287:29134-46. doi:10.1074/jbc.M112.342980

7. Goetz R, Ohnishi M, Ding X, Kurosu H, Wang L, Akiyoshi J, et al. Klotho coreceptors inhibit signaling by paracrine fibroblast growth factor 8 subfamily ligands. Mol Cell Biol (2012) 32:1944-54. doi:10.1128/MCB.06603-11

8. Chen G, Liu Y, Goetz R, Fu L, Jayaraman S, Hu MC, et al. alpha-Klotho is a non-enzymatic molecular scaffold for FGF23 hormone signalling. Nature (2018) 553:461-6. doi:10.1038/nature25451

9. Han X, Yang J, Li L, Huang J, King G, Quarles LD. Conditional deletion of Fgfr1 in the proximal and distal tubule identifies distinct roles in phosphate and calcium transport. PLoS One (2016) 11:e0147845. doi:10.1371/journal. pone. 0147845

10. Shimada T, Mizutani S, Muto T, Yoneya T, Hino R, Takeda S, et al. Cloning and characterization of FGF23 as a causative factor of tumor-induced osteomalacia. Proc Natl Acad Sci U S A (2001) 98:6500-5. doi:10.1073/pnas.101545198

11. Shimada T, Hasegawa H, Yamazaki Y, Muto T, Hino R, Takeuchi Y, et al. FGF-23 is a potent regulator of vitamin D metabolism and phosphate homeostasis. J Bone Miner Res (2004) 19:429-35. doi:10.1359/JBMR.0301264

12. Martin A, David V, Quarles LD. Regulation and function of the FGF23/ Klotho endocrine pathways. Physiol Rev (2012) 92:131-55. doi:10.1152/ physrev.00002.2011

13. Francis F, Hennig S, Korn B, Reinhardt R, de Jong P, Poustka A, et al. A gene (PEX) with homologies to endopeptidases is mutated in patients with X-linked hypophosphatemic rickets. The HYP Consortium. Nat Genet (1995) 11:130-6. doi:10.1038/ng1095-130

14. Bresler D, Bruder J, Mohnike K, Fraser WD, Rowe PS. Serum MEPE-ASARMpeptides are elevated in X-linked rickets (HYP): implications for phosphaturia and rickets. J Endocrinol (2004) 183:R1-9. doi:10.1677/joe.1.05989

15. Martin A, David V, Laurence JS, Schwarz PM, Lafer EM, Hedge AM, et al. Degradation of MEPE, DMP1, and release of SIBLING ASARM-peptides (minhibins): ASARM-peptide(s) are directly responsible for defective mineralization in HYP. Endocrinology (2008) 149:1757-72. doi:10.1210/en. 2007-1205

16. McKee MD, Nanci A. Osteopontin and the bone remodeling sequence. Colloidal-gold immunocytochemistry of an interfacial extracellular matrix protein. Ann N Y Acad Sci (1995) 760:177-89. doi:10.1111/j.1749-6632.1995. tb44629.x

17. Barros NM, Hoac B, Neves RL, Addison WN, Assis DM, Murshed M, et al. Proteolytic processing of osteopontin by PHEX and accumulation of osteopontin fragments in Hyp mouse bone, the murine model of X-linked hypophosphatemia. JBone Miner Res (2013) 28:688-99. doi:10.1002/ jbmr.1766

18. Feng JQ, Ward LM, Liu S, Lu Y, Xie Y, Yuan B, et al. Loss of DMP1 causes rickets and osteomalacia and identifies a role for osteocytes in mineral metabolism. Nat Genet (2006) 38:1310-5. doi:10.1038/ng1905

19. Xiao Z, Huang J, Cao L, Liang Y, Han X, Quarles LD. Osteocyte-specific deletion of Fgfrl suppresses FGF23. PLoS One (2014) 9:e104154. doi:10.1371/ journal.pone.0104154

20. Wohrle S, Henninger C, Bonny O, Thuery A, Beluch N, Hynes NE, et al. Pharmacological inhibition of fibroblast growth factor (FGF) receptor
signalingamelioratesFGF23-mediatedhypophosphatemicrickets.J BoneMiner Res (2013) 28:899-911. doi:10.1002/jbmr.1810

21. Ichikawa S, Austin AM, Gray AK, Econs MJ. A Phex mutation in a murine model of X-linked hypophosphatemia alters phosphate responsiveness of bone cells. J Bone Miner Res (2012) 27:453-60. doi:10.1002/jbmr.544

22. Ichikawa S, Gerard-O’Riley RL, Acton D, McQueen AK, Strobel IE, Witcher PC, et al. A mutation in the Dmp1 gene alters phosphate responsiveness in mice. Endocrinology (2017) 158:470-6. doi:10.1210/en.2016-1642

23. Gutierrez OM. Fibroblast growth factor 23 and disordered vitamin D metabolism in chronic kidney disease: updating the "trade-off" hypothesis. Clin J Am Soc Nephrol (2010) 5:1710-6. doi:10.2215/CJN.02640310

24. Weber TJ, Liu S, Indridason OS, Quarles LD. Serum FGF23 levels in normal and disordered phosphorus homeostasis. J Bone Miner Res (2003) 18:1227-34. doi:10.1359/jbmr.2003.18.7.1227

25. Yoshida T, Fujimori T, Nabeshima Y. Mediation of unusually high concentrations of 1,25-dihydroxyvitamin $\mathrm{D}$ in homozygous Klotho mutant mice by increased expression of renal lalpha-hydroxylase gene. Endocrinology (2002) 143:683-9. doi:10.1210/endo.143.2.8657

26. Shimada T, Kakitani M, Yamazaki Y, Hasegawa H, Takeuchi Y, Fujita T, et al. Targeted ablation of Fgf23 demonstrates an essential physiological role of FGF23 in phosphate and vitamin D metabolism. J Clin Invest (2004) 113:561-8. doi:10.1172/JCI200419081

27. Sitara D, Razzaque MS, Hesse M, Yoganathan S, Taguchi T, Erben RG, et al. Homozygous ablation of fibroblast growth factor-23 results in hyperphosphatemia and impaired skeletogenesis, and reverses hypophosphatemia in Phex-deficient mice. Matrix Biol (2004) 23:421-32. doi:10.1016/j.matbio. 2004.09.007

28. Hesse M, Frohlich LF, Zeitz U, Lanske B, Erben RG. Ablation of vitamin D signaling rescues bone, mineral, and glucose homeostasis in Fgf-23 deficient mice. Matrix Biol (2007) 26:75-84. doi:10.1016/j.matbio.2006.10.003

29. Anour R, Andrukhova O, Ritter E, Zeitz U, Erben RG. Klotho lacks a vitamin $\mathrm{D}$ independent physiological role in glucose homeostasis, bone turnover, and steady-state PTH secretion in vivo. PLoS One (2012) 7:e31376. doi:10.1371/ journal.pone.0031376

30. Streicher C, Zeitz U, Andrukhova O, Rupprecht A, Pohl E, Larsson TE, et al. Long-term Fgf23 deficiency does not influence aging, glucose homeostasis, or fat metabolism in mice with a nonfunctioning vitamin $\mathrm{D}$ receptor. Endocrinology (2012) 153:1795-805. doi:10.1210/en.2011-1878

31. Topaz O, Shurman DL, Bergman R, Indelman M, Ratajczak P, Mizrachi M, et al. Mutations in GALNT3, encoding a protein involved in O-linked glycosylation, cause familial tumoral calcinosis. Nat Genet (2004) 36:579-81. doi:10.1038/ng1358

32. Araya K, Fukumoto S, Backenroth R, Takeuchi Y, Nakayama K, Ito N, et al. A novel mutation in fibroblast growth factor 23 gene as a cause of tumoral calcinosis. J Clin Endocrinol Metab (2005) 90:5523-7. doi:10.1210/jc.20050301

33. Kuro-o M, Matsumura Y, Aizawa H, Kawaguchi H, Suga T, Utsugi T, et al. Mutation of the mouse Klotho gene leads to a syndrome resembling ageing. Nature (1997) 390:45-51. doi:10.1038/36285

34. Ichikawa S, Imel EA, Kreiter ML, Yu X, Mackenzie DS, Sorenson AH, et al. A homozygous missense mutation in human KLOTHO causes severe tumoral calcinosis. J Clin Invest (2007) 117:2684-91. doi:10.1172/JCI31330

35. Gattineni J, Bates C, Twombley K, Dwarakanath V, Robinson ML, Goetz R, et al. FGF23 decreases renal NaPi-2a and NaPi-2c expression and induces hypophosphatemia in vivo predominantly via FGF receptor 1. Am J Physiol Renal Physiol (2009) 297:F282-91. doi:10.1152/ajprenal.90742.2008

36. Andrukhova O, Zeitz U, Goetz R, Mohammadi M, Lanske B, Erben RG. FGF23 acts directly on renal proximal tubules to induce phosphaturia through activation of the ERK1/2-SGK1 signaling pathway. Bone (2012) 51:621-8. doi:10.1016/j.bone.2012.05.015

37. Ornitz DM, Itoh N. The fibroblast growth factor signaling pathway. Wiley Interdiscip Rev Dev Biol (2015) 4:215-66. doi:10.1002/wdev.176

38. Li H, Martin A, David V, Quarles LD. Compound deletion of Fgfr3 and Fgfr4 partially rescues the Hyp mouse phenotype. Am J Physiol Endocrinol Metab (2011) 300:E508-17. doi:10.1152/ajpendo.00499.2010

39. Zhang MY, Ranch D, Pereira RC, Armbrecht HJ, Portale AA, Perwad F. Chronic inhibition of ERK1/2 signaling improves disordered bone and mineral metabolism in hypophosphatemic (Hyp) mice. Endocrinology (2012) 153:1806-16. doi:10.1210/en.2011-1831 
40. Ranch D, Zhang MY, Portale AA, Perwad F. Fibroblast growth factor 23 regulates renal 1,25-dihydroxyvitamin $\mathrm{D}$ and phosphate metabolism via the MAP kinase signaling pathway in Hyp mice. J Bone Miner Res (2011) 26:1883-90. doi:10.1002/jbmr.401

41. Meyer MB, Benkusky NA, Kaufmann M, Lee SM, Onal M, Jones G, et al. A kidney-specific genetic control module in mice governs endocrine regulation of the cytochrome P450 gene Cyp27b1 essential for vitamin D3 activation. J Biol Chem (2017) 292:17541-58. doi:10.1074/jbc.M117.806901

42. Shimada T, Yamazaki Y, Takahashi M, Hasegawa H, Urakawa I, Oshima T, et al. Vitamin D receptor-independent FGF23 actions in regulating phosphate and vitamin D metabolism. Am J Physiol Renal Physiol (2005) 289:F1088-95. doi:10.1152/ajprenal.00474.2004

43. Jones G, Prosser DE, Kaufmann M. 25-Hydroxyvitamin D-24-hydroxylase (CYP24A1): its important role in the degradation of vitamin D. Arch Biochem Biophys (2012) 523:9-18. doi:10.1016/j.abb.2011.11.003

44. Inoue Y, Segawa H, Kaneko I, Yamanaka S, Kusano K, Kawakami E, et al. Role of the vitamin D receptor in FGF23 action on phosphate metabolism. Biochem J (2005) 390:325-31. doi:10.1042/BJ20041799

45. Deliot N, Hernando N, Horst-Liu Z, Gisler SM, Capuano P, Wagner CA, et al. Parathyroid hormone treatment induces dissociation of type IIa Na+$\mathrm{P}(\mathrm{i})$ cotransporter- $\mathrm{Na}+/ \mathrm{H}+$ exchanger regulatory factor-1 complexes. Am J Physiol Cell Physiol (2005) 289:C159-67. doi:10.1152/ajpcell.00456.2004

46. Weinman EJ, Biswas RS, Peng G, Shen L, Turner CL, Xiaofei E, et al. Parathyroid hormone inhibits renal phosphate transport by phosphorylation of serine 77 of sodium-hydrogen exchanger regulatory factor-1. J Clin Invest (2007) 117:3412-20. doi:10.1172/JCI32738

47. Andrukhova O, Bayer J, Schuler C, Zeitz U, Murali SK, Ada S, et al. Klotho lacks a FGF23 independent role in mineral homeostasis. J Bone Miner Res (2017) 32:2049-61. doi:10.1002/jbmr.3195

48. Andrukhova O, Smorodchenko A, Egerbacher M, Streicher C, Zeitz U, Goetz R, et al. FGF23 promotes renal calcium reabsorption through the TRPV5 channel. EMBO J (2014) 33:229-46. doi:10.1002/embj.201284188

49. Andrukhova O, Slavic S, Smorodchenko A, Zeitz U, Shalhoub V, Lanske B, et al. FGF23 regulates renal sodium handling and blood pressure. EMBO Mol Med (2014) 6:744-59. doi:10.1002/emmm.201303716

50. Andrukhova O, Streicher C, Zeitz U, Erben RG. Fgf23 and parathyroid hormone signaling interact in kidney and bone. Mol Cell Endocrinol (2016) 436:224-39. doi:10.1016/j.mce.2016.07.035

51. de Groot T, Lee K, Langeslag M, Xi Q, Jalink K, Bindels RJ, et al. Parathyroid hormone activates TRPV5 via PKA-dependent phosphorylation. J Am Soc Nephrol (2009) 20:1693-704. doi:10.1681/ASN.2008080873

52. Gupta A, Winer K, Econs MJ, Marx SJ, Collins MT. FGF-23 is elevated by chronic hyperphosphatemia. J Clin Endocrinol Metab (2004) 89:4489-92. doi:10.1210/jc.2004-0724

53. Geller JL, Khosravi A, Kelly MH, Riminucci M, Adams JS, Collins MT. Cinacalcet in the management of tumor-induced osteomalacia. J Bone Miner Res (2007) 22:931-7. doi:10.1359/jbmr.070304

54. Shalhoub V, Shatzen EM, Ward SC, Davis J, Stevens J, Bi V, et al. FGF23 neutrali zation improves chronic kidney disease-associated hyperparathyroidism yet increases mortality. J Clin Invest (2012) 122:2543-53. doi:10.1172/JCI61405

55. Kinoshita Y, Fukumoto S. X-linked hypophosphatemia and FGF23-related hypophosphatemic diseases - prospect for new treatment. Endocr Rev (2018). doi:10.1210/er.2017-00220

56. Murali SK, Roschger P, Zeitz U, Klaushofer K, Andrukhova O, Erben RG. FGF23 regulates bone mineralization in a 1,25(OH) D and Klotho-independent manner. J Bone Miner Res (2016) 31:129-42. doi:10.1002/jbmr.2606

57. Addison WN, Azari F, Sorensen ES, Kaartinen MT, McKee MD. Pyrophosphate inhibits mineralization of osteoblast cultures by binding to mineral, up-regulating osteopontin, and inhibiting alkaline phosphatase activity. J Biol Chem (2007) 282:15872-83. doi:10.1074/jbc.M701116200

58. Shalhoub V, Ward SC, Sun B, Stevens J, Renshaw L, Hawkins N, et al. Fibroblast growth factor 23 (FGF23) and alpha-Klotho stimulate osteoblastic MC3T3. E1 cell proliferation and inhibit mineralization. Calcif Tissue Int (2011) 89:140-50. doi:10.1007/s00223-011-9501-5

59. Miyagawa K, Yamazaki M, Kawai M, Nishino J, Koshimizu T, Ohata Y, et al. Dysregulated gene expression in the primary osteoblasts and osteocytes isolated from hypophosphatemic Hyp mice. PLoS One (2014) 9:e93840. doi:10.1371/journal.pone.0093840

60. Murali SK, Andrukhova O, Clinkenbeard EL, White KE, Erben RG. Excessive osteocytic Fgf23 secretion contributes to pyrophosphate accumulation and mineralization defect in hyp mice. PLoS Biol (2016) 14:e1002427. doi:10.1371/ journal.pbio. 1002427

61. Coe LM, Madathil SV, Casu C, Lanske B, Rivella S, Sitara D. FGF-23 is a negative regulator of prenatal and postnatal erythropoiesis. JBiol Chem (2014) 289:9795-810. doi:10.1074/jbc.M113.527150

62. Agoro R, Montagna A, Goetz R, Aligbe O, Singh G, Coe LM, et al. Inhibition of fibroblast growth factor 23 (FGF23) signaling rescues renal anemia. FASEB J (2018):fj201700667R. doi:10.1096/fj.201700667R

63. Yamashita T, Yoshioka M, Itoh N. Identification of a novel fibroblast growth factor, FGF-23, preferentially expressed in the ventrolateral thalamic nucleus of the brain. Biochem Biophys Res Commun (2000) 277:494-8. doi:10.1006/ bbrc. 2000.3696

64. Hensel N, Schon A, Konen T, Lubben V, Forthmann B, Baron O, et al. Fibroblast growth factor 23 signaling in hippocampal cells: impact on neuronal morphology and synaptic density. J Neurochem (2016) 137:756-69. doi:10.1111/jnc. 13585

65. Olauson H, Lindberg K, Amin R, Sato T, Jia T, Goetz R, et al. Parathyroidspecific deletion of Klotho unravels a novel calcineurin-dependent FGF23 signaling pathway that regulates PTH secretion. PLoS Genet (2013) 9:e1003975. doi:10.1371/journal.pgen.1003975

66. Ben Dov IZ, Galitzer H, Lavi-Moshayoff V, Goetz R, Kuro-o M, Mohammadi M, et al. The parathyroid is a target organ for FGF23 in rats. J Clin Invest (2007) 117:4003-8. doi:10.1172/JCI32409

67. Faul C, Amaral AP, Oskouei B, Hu MC, Sloan A, Isakova T, et al. FGF23 induces left ventricular hypertrophy. J Clin Invest (2011) 121:4393-408. doi:10.1172/JCI46122

68. Grabner A, Amaral AP, Schramm K, Singh S, Sloan A, Yanucil C, et al. Activation of cardiac fibroblast growth factor receptor 4 causes left ventricular hypertrophy. Cell Metab (2015) 22:1020-32. doi:10.1016/j.cmet.2015. 09.002

69. Slavic S, Ford K, Modert M, Becirovic A, Handschuh S, Baierl A, et al. Genetic ablation of Fgf23 or Klotho does not modulate experimental heart hypertrophy induced by pressure overload. Sci Rep (2017) 7:11298. doi:10.1038/ s41598-017-10140-4

Conflict of Interest Statement: The author declares that the research was conducted in the absence of any commercial or financial relationships that could be construed as a potential conflict of interest.

Copyright (C) 2018 Erben. This is an open-access article distributed under the terms of the Creative Commons Attribution License (CC BY). The use, distribution or reproduction in other forums is permitted, provided the original author(s) and the copyright owner are credited and that the original publication in this journal is cited, in accordance with accepted academic practice. No use, distribution or reproduction is permitted which does not comply with these terms. 